\title{
Hybrid Wing Body (HWB) Slat Noise Analysis
}

\author{
Yueping Guo* \\ Boeing Research \& Technology, Huntington Beach, CA 92647 \\ Leon Brusniak ${ }^{\dagger}$ and Michael Czech ${ }^{\ddagger}$ \\ Boeing Commercial Airplane, P.O. Box 3707, Everett, WA \\ and \\ Russell H. Thomas ${ }^{\S}$ \\ NASA Langley Research Center, Hampton, VA 23681
}

\begin{abstract}
This paper presents an analysis of the slat noise for Hybrid Wing Body (HWB) aircraft, based on a database from a $3 \%$ scale wind tunnel test. It is shown that the HWB slats are one of the dominant noise components, characterized by its broad spectral shape with a peak frequency that depends on both the mean flow velocity and the aircraft angle of attack, the former following the conventional Strouhal number scaling and the latter explainable by the dependence of the coherence length of the slat unsteady flows on the aircraft angle of attack. While the overall levels of the slat noise are shown to approximately follow the fifth power law in the flow Mach number, the effects of the Mach number manifest themselves in the noise spectra in both the amplitude and the spectral shape. The slat noise amplitude is shown to also depend on the angle of attack, assuming a minimum in the range of 3 to 5 degrees and increasing when the angle of attack moves away from this range. These features are all modeled and incorporated in slat noise prediction methodologies, extending the prediction capability from conventional aircraft designs to HBW configurations. Comparisons between predictions and data show very good agreements both in various parametric trends and in the absolute levels. The HWB aircraft is designed to operate at angles of attack much higher than those of conventional aircraft. This is shown to significantly increase the HWB slat noise. To further illustrate, the test data are extrapolated to full scale and compared with the slat noise of the Boeing 777 aircraft, showing that the former is higher the latter.
\end{abstract}

\section{Introduction}

Hybrid Wing Body (HWB) aircraft has been attracting much attention in recent years because of its potential for reducing aircraft engine noise by mounting the engines on the upper surface of the airframe structure, shielding the engine noise from the ground (e.g. Ref 1-6). This may significantly reduce the engine noise components, but the effectiveness in reducing the total aircraft noise will also depend on the levels of the non-propulsion related components, including the noise from the HWB airframe structure and that from the landing gears. These components may form a noise floor that holds up the total noise levels. In this case, it may not have added value to trade aerodynamic performance and/or propulsion efficiency to increase the noise shielding, by shifting the engine installation further upstream of the trailing edge, for example, before the airframe noise is reduced. Thus, it is important to reliably assess the levels of HWB airframe noise, which is necessary not only to demonstrate the total acoustic benefit of the HWB design, but also to guide future developments of HWB acoustic technologies, especially in the area of airframe-propulsion integration.

To this end, this paper presents an analysis of the HWB slat noise, one of the major airframe noise components for the HWB aircraft. Due to their designed functionality of providing high lift in aircraft takeoff and landing

\footnotetext{
* Technical Fellow, Acoustics Technology, 5301 Bolsa Ave, Huntington Beach, CA, AIAA Associate Fellow

${ }^{\dagger}$ Engineer, Acoustics Technology, P.O. Box 3707, MC OR-JF, Seattle, WA

*Engineer, Acoustics Technology, P.O. Box 3707, MC OR-JF, Seattle, WA

${ }^{\S}$ Senior Research Engineer, Aeroacoustics Branch, MS 461, AIAA Senior Member
} 
operations, leading edge slats in both conventional and HWB aircraft generate noise by similar mechanisms, namely, the cove region flow separation and the high speed unsteady flows in the gap between the slat trailing edge and the main wing (e.g. Ref 7-10). Thus, the basic characteristics of the noise can be expected to follow similar patterns for both. However, the design details and the operating conditions of the two types of aircraft are different, potentially leading to differences in the parametric trends and amplitudes of the noise.

For the spectral features, it will be shown that the slat noise is broadband, with the frequency of the spectral peak scaling on the mean flow velocity. At fixed mean flow velocity, the peak frequency will be shown to vary with the aircraft angle of attack, shifting upwards as the angle of attack increases from zero to the slat deployment angle. This does not follow the Strouhal number scaling based on the slat chord length, which would determine the peak frequency entirely by the mean flow velocity and the chord length. This scaling has proven useful for conventional aircraft slat noise, as discussed in previous studies (e.g. Ref 7-10), because the variations in the angle of attack in that case are small, typically about from 4 to 7 degrees at approach conditions. The HWB aircraft, however, may operate at angles of attack usually above 10 degrees and can be as high as 14 degrees. At such large angles of attack, the Strouhal number scaling based on the slat chord does not seem to collapse the peak frequency to the usual value of about 2, and when considering the whole range of angles of attack, from zero to 15 degrees, for example, it becomes apparent that the peak frequency is not invariant for fixed mean flow velocity and chord length. This will be argued to result from the deficiency of using the slat chord as the characteristic length scale of the unsteady flows. This characteristic length scale should depend on other flow conditions such as the angle of attack, instead of a fixed value based solely on the geometry such as the chord length. When the flow-dependent length parameter is used in the Strouhal number scaling, the dependence of the peak frequency on the angle of attack then becomes clear. The use of flow-dependent length scales in Strouhal number scaling has previously been used in other studies (Ref 11, 12).

The noise amplitudes will be shown to depend on both the flow Mach number and the aircraft angle of attack. For the flow Mach number, the features are very similar to those for conventional aircraft discussed in Ref 8 . The overall sound pressure levels approximately scale on the fifth power law in Mach number, but the effects of the Mach number on the noise spectra are more complicated. The spectral amplitudes do not seem to scale on any simple power law, even though they are in general an increasing function of the Mach number. This is due to the dependence of the spectral shapes on the Mach number. The variations of the noise amplitude with the angle of attack will be shown to assume a minimum in the range of about 3 to 5 degrees, with increasing levels when the angle of attack moves away from this range. It can be noted that the range of the angle of attack for the minimum slat noise is close to the usual operation range of conventional aircraft. This gives the HWB configuration, usually designed to operate at high angles of attack above 10 degrees, an acoustic disadvantage because the increase in slat noise due to the increase in the angle of attack can be significant, as high as $8 \mathrm{~dB}$. This, together with the larger sizes and the larger sweep angles of the HWB slats, compared to conventional aircraft designs, makes the slat noise one of the dominant components of HWB airframe noise.

Based on the parametric trends revealed by the data, the features such as the effects of the angles of attack on the noise amplitude and its peak frequency will be modeled for slat noise prediction. Methodologies for slat noise prediction have so far mostly been based on conventional aircraft (e.g. Ref 7, 8), and hence, have been focused on operations with the angle of attack in the range of 4 to 7 degrees. The model developed here will be incorporated into the method developed in Ref 8, extending its prediction capability from conventional aircraft designs to HWB configurations. The prediction models will be used to predict the HWB slat noise, including the parametric trends in spectral shape, Mach number dependence, and variations with the angle of attack. It will be shown that the predictions agree well with the HWB test data in both the parametric trends and the absolute levels.

For conventional aircraft, the high lift systems include trailing edge flaps, whose side edge noise is known to be a major airframe noise component (Ref 11-14) with amplitude comparable to or higher than the slat noise, making the slat noise component a less important priority in airframe noise technologies. For HWB aircraft, however, trailing edge flaps are not used, and hence, flap side edge noise is absent, increasing the relative importance of slat noise in the ranking order of HWB noise components. To further demonstrate the importance of HWB slat noise and to quantify the levels of this component, the data from the small scale model test are extrapolated to full scale, to an aircraft comparable to the Boeing 777 aircraft in size and functionality. It will be shown that the HWB aircraft slats generate substantially more low frequency noise then the Boeing 777 aircraft, in the frequency domain around 100 $\mathrm{Hz}$, by as much as $10 \mathrm{~dB}$, because the HWB slats have larger chord length. In the frequency range from about 100 $\mathrm{Hz}$ to $1000 \mathrm{~Hz}$, the HWB slat noise is higher than that of the Boeing 777 aircraft by about $2 \mathrm{~dB}$. The higher levels of the HWB slat noise may seem to be a surprise because it operates at a lower Mach number, 0.2 for the HWB aircraft compared with 0.25 for the Boeing 777, which would lead to lower HWB slat noise according to the fifth power law on Mach number. However, this simple reasoning, based solely on the flight Mach number, fails to account for 
features such as the slat sweep angle and the aircraft angle of attack, for both of which, the HWB aircraft has larger values. Obviously, larger values of both the slat sweeping angle and the angle of attack may lead to more intense flow separation in the slat flow region (e.g. Ref 7-10), and hence, lead to more slat noise generation. The test data and analysis presented here confirm this and show that the acoustic benefit of lower flight Mach number for the HWB aircraft is more than offset by its large angles of attack and large sweep angle.

\section{LSAF Experimental Description}

The HWB airframe noise experiment was performed in May of 2009, one of two back-to-back experiments in the Boeing Low Speed Aeroacoustics Facility (LSAF) to understand key aspects of hybrid wing body (HWB) acoustics and to support system noise assessments of low noise designs of HWB aircraft concepts. The second experiment included the jet noise shielding aspect of a hybrid wing body and the development of nozzle configuration technology to increase the shielding effectiveness for the jet noise source (Ref 4). Data from both experiments have been used in system noise assessments by NASA (Ref 3 ) and by Boeing (Ref 5,6) showing the potential of the HWB to reach the NASA N+2 noise goal of $42 \mathrm{~dB}$ cumulative below Stage 4 given the technology selections described.

The airframe model is a 3\% scale of the Boeing Blended-Wing-Body (BWB) 450-1L design by Liebeck (Ref 15). The 450-1L was designed as a state-of-the-art configuration, and at the time when the HWB airframe noise experiment was planned in 2008, it still represented one of the best configuration and aerodynamic designs for a hybrid wing body aircraft concept. A realistic, high fidelity design of the airframe is essential for realistic airframe noise characteristics. The model was built by NASA in the year 2000 based on the Boeing design and was originally built for low speed aerodynamic and flight dynamic testing. The model was used in several NASA wind tunnel campaigns including the NASA Langley 14 by 22 Foot Subsonic Wind Tunnel. In fact, this $3 \%$ model was used to develop the bulk of the low speed aerodynamic database obtained by NASA and Boeing for this 450-1L design (Ref 16). In the 2008 planning of this HWB airframe noise experiment, this model was in excellent condition and available, had considerable aerodynamic data associated with it, and also it represented a state-of-the-art design with which NASA and Boeing had developed a large amount of experience over the prior 10-15 years of joint research.

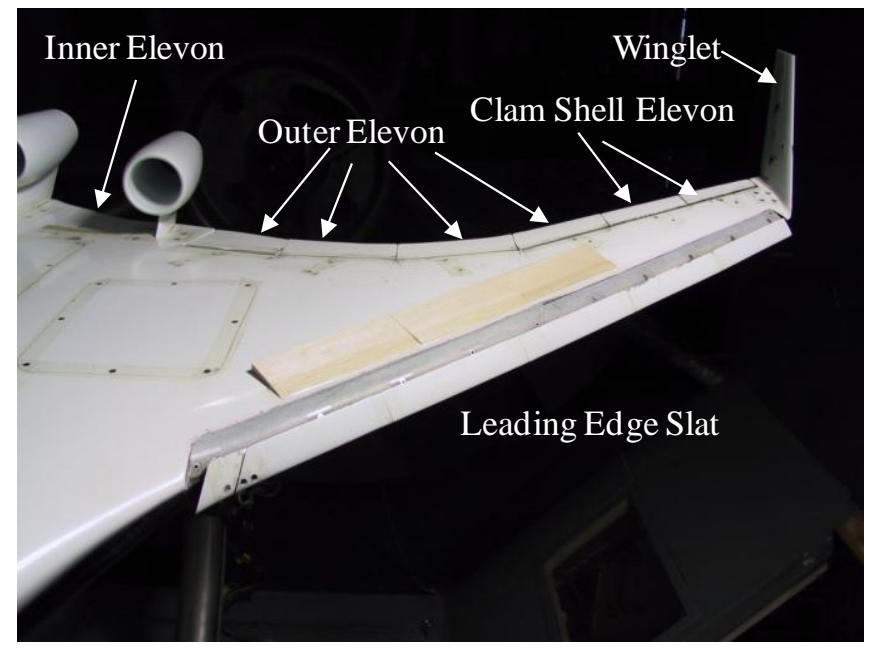

Figure 1 Aerodynamic control surfaces and leading edge slats of the 3\% HWB model.

The model is 89.02 inches in span and is a $3 \%$ scale of a $247 \mathrm{ft}$ span full-scale design of the $450-1 \mathrm{~L}$. This full size concept had three engines mounted with the nozzle exhausts downstream of the trailing edge. While this $450-1 \mathrm{~L}$ design represents a state-of-the-art HWB, it was not designed with a low aircraft system noise goal in mind and, therefore, has this one key feature of the position of the engines as a difference from subsequent low noise designs. With very little other HWB airframe noise information available at the time of this research, the use of this model was an excellent choice even though the position of the flow through engine nacelles was inconsistent with the subsequent low noise designs. The flow-through nacelles are insignificant as an airframe noise source. Figure 1 shows the identification of the aerodynamic control surfaces that are included on the model from the full-scale design. Inboard and outboard control elevons cover the length of the trailing edge. The outer most two elevons can 
also split to form a drag rudder. The winglets also include a rudder. Leading edge slats are incorporated for high lift. Landing gears were not available for this model.

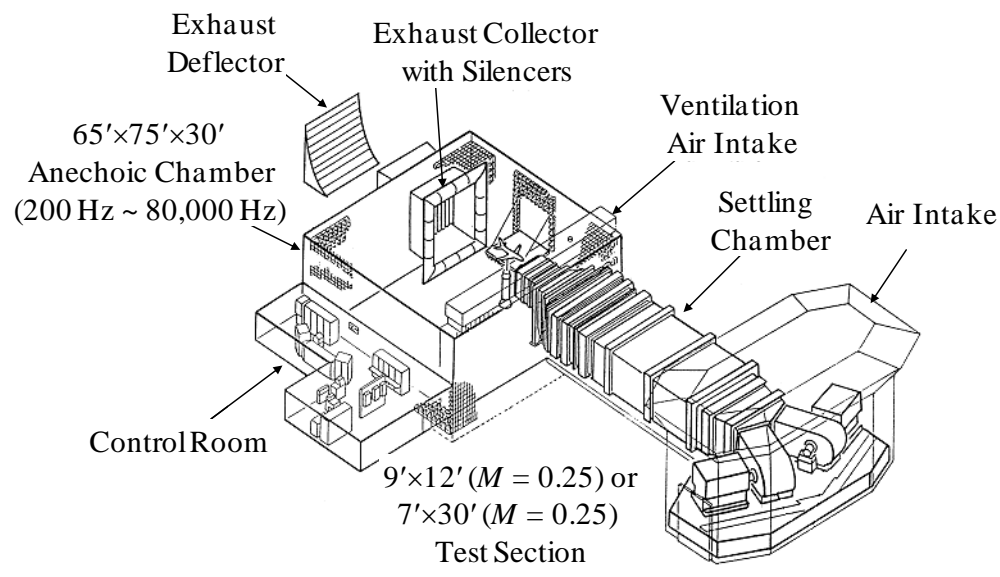

Figure 2 Boeing's Low Speed Aeroacoustic Facility (LSAF).

The experimental facility was the Boeing Low Speed Aeroacoustic Facility (LSAF) as schematically shown in Figure 2. The LSAF was configured with a 9 by 12 foot open jet test section in order to have the largest test section possible given that the 3\% model is a large model for this test section. Free-field Brüel \& Kjær Type 4939 microphones were set up to measure a polar angle range from 50 to 150 degrees. Three different arrays were deployed simultaneously to also measure the azimuthal variation of the sound field at angles of 90,60 and 30 degrees. The array at 90 degrees was laid out in a polar arc at radius (R) of $25 \mathrm{ft}$. The 30 and 60 degree azimuthal arrays were at a constant sideline distance of $17.6 \mathrm{ft}$ and $7.9 \mathrm{ft}$ respectively. The atmospheric attenuation coefficients were obtained from the method of Shields and Bass (Ref 17). The spectral data presented in this paper are model scale data unless otherwise noted.

The 3\% model of the BWB planform was installed from above the test section on an overhead structure with an aerodynamic, smooth blade strut attachment to the airframe using a standard location for this model. In this way, the model could be pitched to angle-of-attack as well as be traversed in two dimensions in a plane normal to the airframe model as shown in Figure 3. The precise positioning of the airframe was monitored with photogrammetry and was determined to be within 0.05 inches.

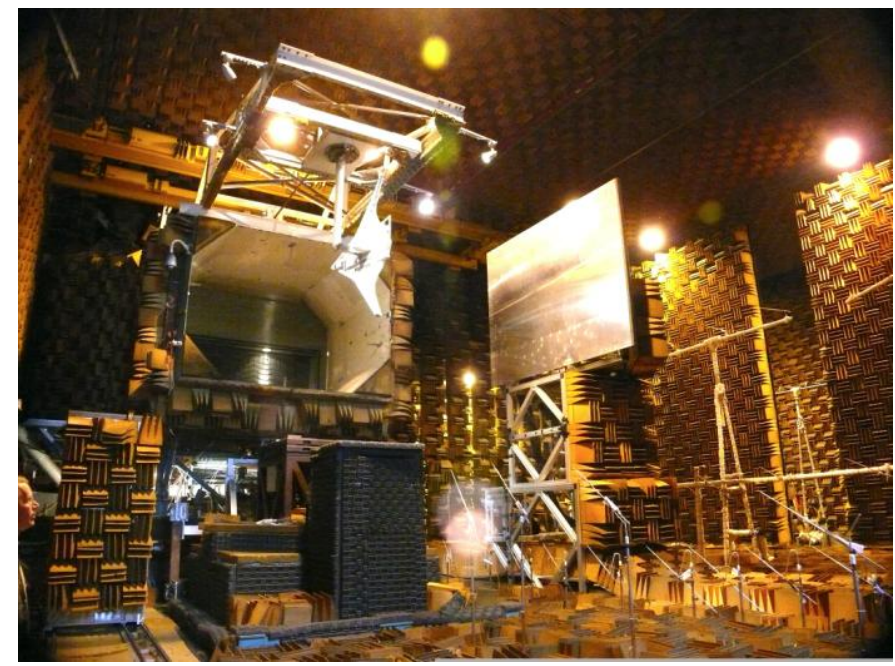

Figure 3 Photograph of the LSAF experimental setup for the HWB airframe noise experiment. 
Figure 3 also shows the phased array panel that can traverse downstream of the tunnel nozzle exit plane. When not deployed, the phased array panel is stowed upstream of the nozzle exit plane so as to not interfere with the far field microphones which are also shown in Figure 3. Figure 4 is a photograph taken from the opposite direction of the installed model and shows the underside or pressure side of the HWB airframe. Tape is seen on the model and was used to smooth over cover attachments and to eliminate some gaps that would not be present in a full scale application.

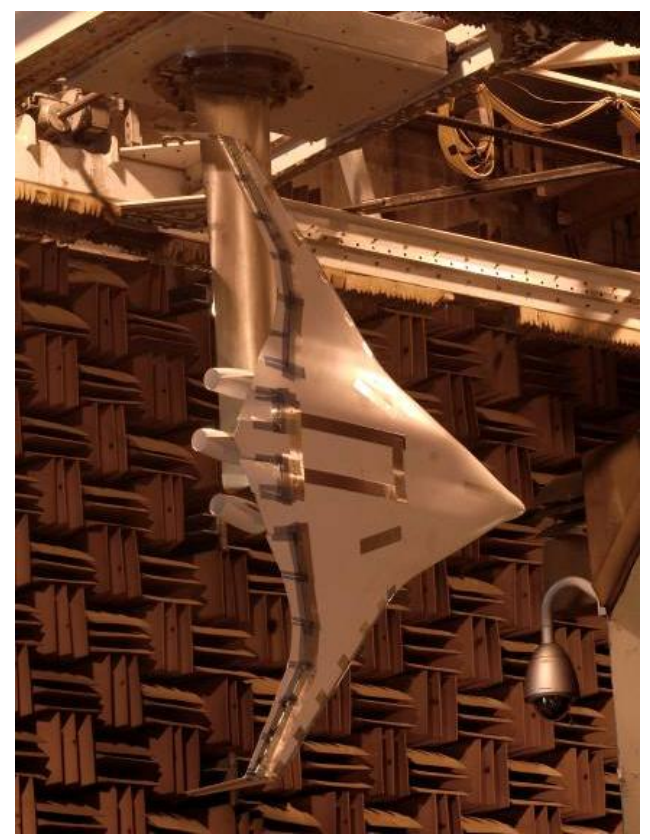

Figure 4 Underside view of the 3\% HWB airframe in the Boeing LSAF

\section{LSAF Phased Array Data Reduction Process}

Phased microphone arrays were used to locate and quantify the levels of the acoustic sources for a large fraction of the testing. The phased array consisted of 416 Brüel \& Kjær 1/4-inch type 4938-W-001 microphones, with B\&K 2670-W-001 preamplifiers, flush mounted in a flat plate positioned 131.6 inches laterally from the stream-wise oriented vertical plane passing through the far-field microphone array origin in the polar angle plane, as illustrated in Figure 5. The plate was attached to a mobile cart which was mounted on a horizontal traversing track (which traversed parallel to the wind tunnel flow direction), allowing for a wide range of phased array positions relative to the polar array origin. Phased array measurements were acquired largely at geometric angles $50^{\circ}, 70,90^{\circ}, 110^{\circ}, 130$ and $150^{\circ}$, and a limited set of measurements were acquired from $50^{\circ}$ to $150^{\circ}$ in $10^{\circ}$ increments. When acquiring far field acoustic data, the cart was traversed to a stow location behind the tunnel contraction.

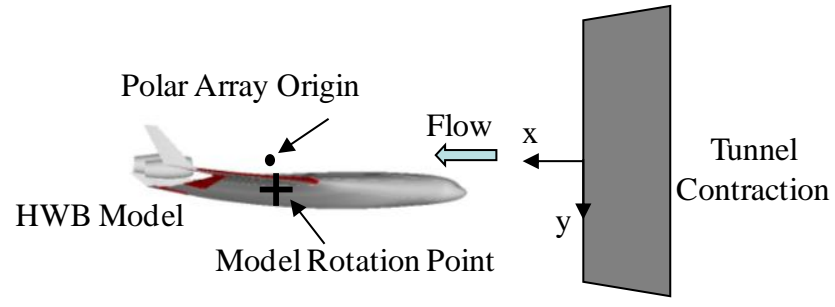

Phased Array

Figure 5 Illustration of Boeing's LSAF test setup for HWB airframe noise

The BWB model rotation axis was located at $(x, y, z)=(81.94,15.0,11.75)$ inches, in wind tunnel coordinates. For a phased array angle of $90^{\circ}$, the phased array origin was located at an $x$ value of 100.439 inches, approximately 
18 inches downstream of the model rotation point. The relative locations of the phased array, the model and the tunnel exit are sketched in Figure 5. The phased array consisted of four sub-arrays of various sizes, where the subarrays provided overlapping coverage over the frequency range of interest. The four sizes are referred to as: small (S), medium (M), large (L) and extra large (XL), with the baseline sub-arrays containing, respectively, 170, 199, 110 and 170 microphones. The horizontal/vertical sub-array apertures were approximately 12 inch $\times 9$ inch (S), 26.2 inch $\times 19.8$ inch $(\mathrm{M}), 57.6$ inch $\times 43.6$ inch $(\mathrm{L})$ and 126 inch $\times 95.6$ inch $(\mathrm{XL})$ in size. A sharing of microphones between the various sub-arrays was used to reduce the overall microphone count. Conventional beamforming was used for all of the phased array processing. In order to enhance the spatial resolution in the beamforming maps, the diagonal of the cross-spectral matrix was replaced by the row average. The properties of the four sub-arrays are summarized in Table 1.

Table 1 Properties of sub-arrays

\begin{tabular}{lcccc}
\hline \multicolumn{1}{c}{ Size } & Symbol & Frequency Range (Hz) & Aperture Size (in) & \# of Microphones \\
Extra Large & $\mathrm{X}$ & $700-3330$ & $126 \times 95.6$ & 170 \\
Large & $\mathrm{L}$ & $3330-6670$ & $57.6 \times 43.6$ & 110 \\
Medium & $\mathrm{M}$ & $6670-13300$ & $26.2 \times 19.8$ & 199 \\
Small & $\mathrm{S}$ & $13300-33300$ & $12 \times 9$ & 170 \\
\hline
\end{tabular}

Owing to the presence of the wind tunnel shear layer, a ray tracing algorithm was used (Ref 18). In the implemented algorithm, the shear layer half-velocity distribution at any given $x$ location cross-section was modeled as an ellipse. This model worked fairly well over a wide range of phased array geometric measurement angles. At the extreme angles (approximately $50^{\circ}$, and larger than $\sim 130^{\circ}$ ), shifts in the measured source locations from the expected locations arose, and are attributed to increased differences between the modeled and actual shear layer location and shape.
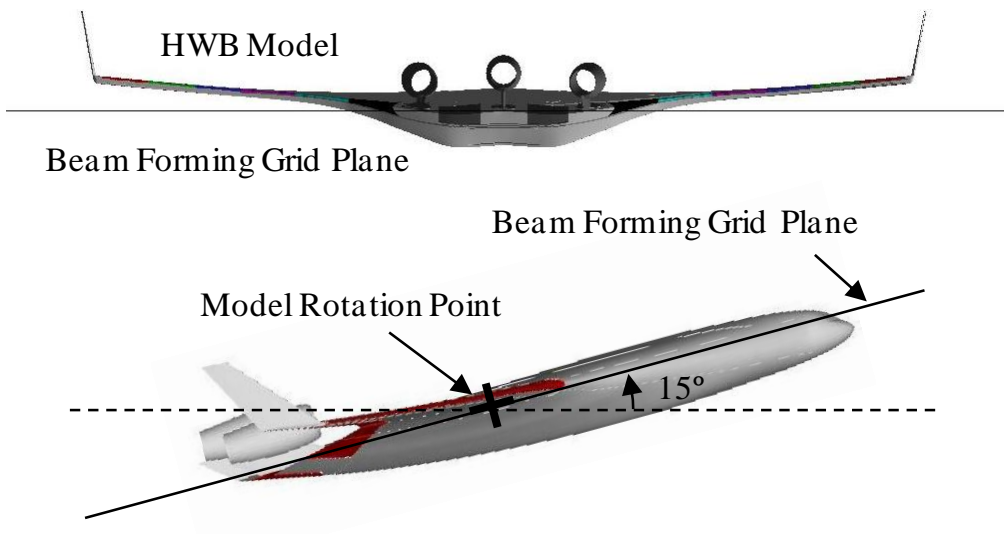

Figure 6 Phased array beamforming grid plane in reference to the HWB airframe model; forward view (upper) and side view (lower)

The beamforming grid was a rectangular grid with 0.5 inch separation between grid points in both the $x$ and $z$ dimensions. The grid center was fixed in space and located at the model rotation point, illustrated in Figure 6. In this configuration, the grid was relatively close to the primary noise sources of interest (which extended both above and below the grid plane). To account for the various model angles of attack $\left(0^{\circ}, 4^{\circ}, 8^{\circ}, 10^{\circ}, 12^{\circ}, 13^{\circ}\right.$ and $\left.15^{\circ}\right)$, the grid was likewise pitched with the model. The lower plot in Figure 6 shows a side view schematic of the grid for a $15^{\circ}$ angle of attack.

For the subcomponent spectra extractions, a variety of subcomponent regions were defined as sketched qualitatively in Figure 7. The regions for the component integration need to be defined according to the test configurations, even though the definitions of the components such as leading edge slats and trailing edge elevons 
remain unchanged. This is illustrated by the three plots in Figure 7, respectively for the ideal case (the left plot), the case with the slats deployed (the middle plot) and the case with the slats extracted (the right plot). For all three cases, the regions 1 to 4 are the same and are not related to the airframe noise components; regions 1 accounts for the contamination noise source due the interaction between the upper wing of the model and the test section shear flow, regions 2 and 3 are used to track some flow noise sources that appear at some test conditions, and region 4 is used to provide information on noise floor levels. The regions labeled 5 and 6 are also the same for all three cases, and encompass part of the model center body and center trailing edge respectively.

For the ideal configuration shown in the left plot in Figure 7, for which all noise sources would be of similar levels and would be well separated spatially, each subcomponent region would be defined as shown by the white lined regions, which essentially follow the definitions of the airframe components. For example, the regions 7 and 9 would be defined respectively for the leading edge slats and the trailing edge elevons for the lower wing with the two regions separated at the mid chord of the wing. The regions for the components on the upper wing would be similarly defined, with region 10 covering the geometry of the trailing edges and region 12 covering the leading edges. For the slat noise sources, the regions are defined as region 13 and 16, as shown in the middle plot in Figure 7. It should be noted that the region 16 for the upper wing is not truly slat noise; it is due to the interactions at the top of the model between the wing and the test section shear layer flows, which is an artifact resulting from the wind tunnel size limitation. In this case, the slat noise from the upper wing can be derived from region 13, as a mirror image. For the slat retracted configuration, shown in the plot on the right in Figure 7, the model trailing edge is the primary noise source with no contributions from the leading edge. Hence the region for the component integration, regions 17 and 18, is allowed to extend upstream of the wing leading edge. Similarly to region 16 for the slat deployed case, region 18 could include noise from the wing/shear layer interaction and should be excluded from the airframe noise analysis. The trailing edge noise from the upper wing in this case can be derived from region 17 as a mirror image.
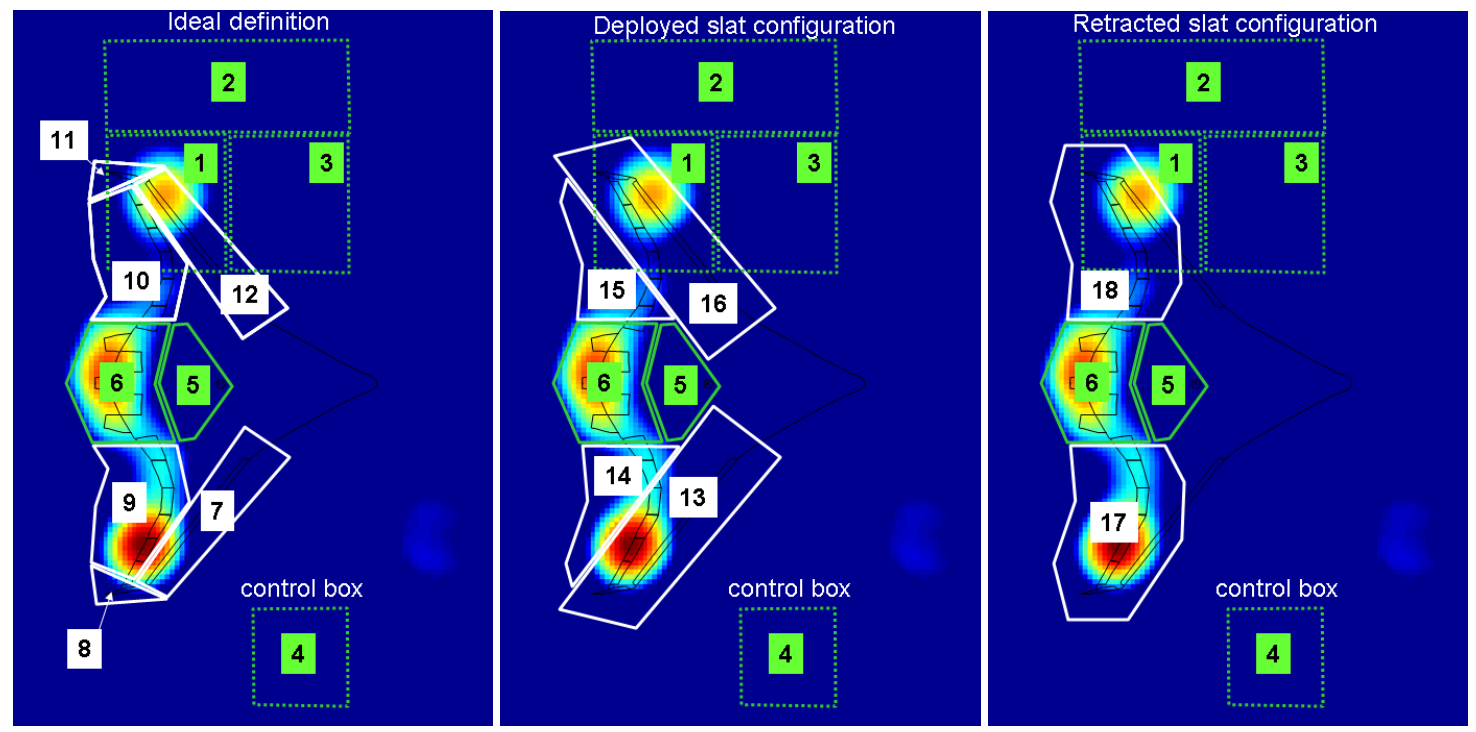

Figure 7 Definitions of surface regions for component noise integration with the left diagram for the ideal case, the middle diagram for slat deployed case and the right diagram for the slat retracted case

Extracted subcomponent spectra include the peak levels in each of the 18 defined regions and the integrated levels. See Ref 18 for a description of the beamforming map integration method. For producing total airframe noise levels, the spectral levels from regions 5 and 6 can be taken in their entirety and summed with a doubling of the values from the lower half of the airframe (e.g., for the plot on the right of Figure 7, doubling the region 17 levels to account for the region 18 levels which are likely contaminated by wing/shear layer interaction noise, and similarly for the slat deployed configurations).

\section{Comparison with Free Field Microphone Data}

In addition to the phased array measurements, free field microphones were also used in the test, deployed in a line in the flyover plane. The free field microphone data were used to acquire quantitative far field noise levels to 
provide an accurate assessment of the HWB airframe noise. However, the HWB model, which is a preexisting model from previous studies, is larger than the wind tunnel test section. A compromise was made to resolve this issue by installing the model off the test section center so that one wing of the HWB model is in the test section uniform mean flow, but the other protrudes into the shear layer of the open jet. This inevitably introduces an unwanted noise component due to the shear layer impinging onto the HWB wing. The model set up and the potential noise sources are illustrated in Figure 8. As a result, the free field microphone data are contaminated by this unwanted noise component. This was considered in the test planning as a necessary compromise with reduced expectations for the free field microphone data; the data will not be able to give an accurate level for the HWB airframe noise. The free field microphone data, however, can still be used to calibrate the phased microphone array measurements by comparing the free microphone data that include noise from all sources with the phased array data integrated over the entire beamforming map, and hence, also including contributions from all sources. The phased array can then be used to extract various noise components, by integration of the phased array beamforming results in individual source regions, which are free from the contamination due to the wing-shear layer interaction and are relevant to HWB component airframe noise.

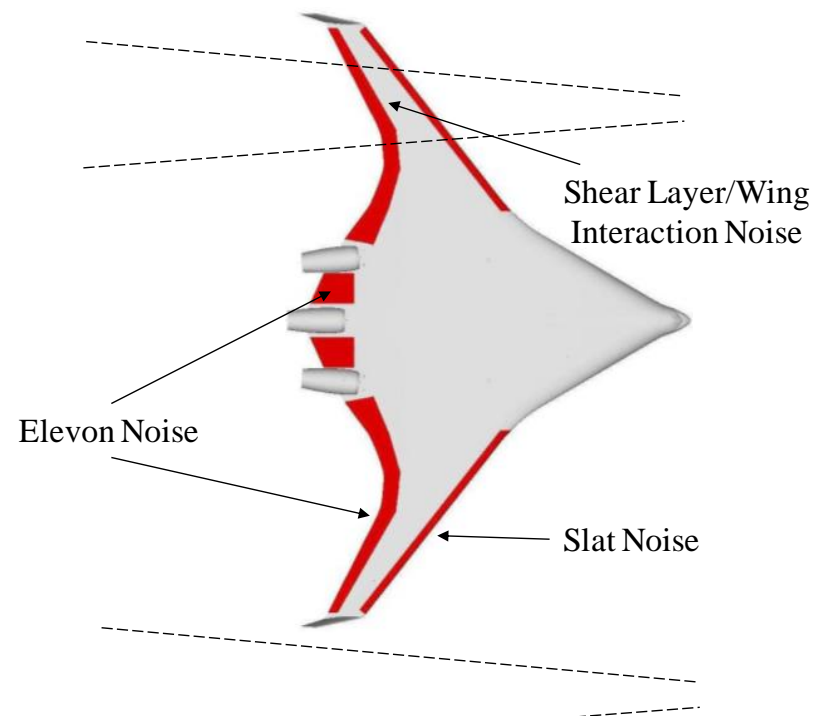

\section{Figure 8 Installation of HWB model in test section bounded by shear layers}

To illustrate the accuracy and consistency of the phased array measurements, when used to derive far field spectral data, some examples are given in Figure 9 and Figure 10, respectively for zero and 13 degrees of angle of attack. The data plotted in these two figures are the $1 / 3$ octave sound pressure levels at 90 degrees of emission angle in the flyover plane. The results shown in these two figures are for the case of the Mach number of 0.2, which is the designed flight Mach number of the HWB aircraft. The results are very representative of other Mach numbers. The HWB configuration for these data has the leading edge slats deployed at 30 degrees. The phased array results in the comparison are the integration of the beamforming maps over all the source regions. In the test setup, the array and the free field microphones are at different distances from the test model, respectively at 11 and 25 feet from the model center at the angle of 90 degrees. The comparisons shown in the two figures are for array measurements that are normalized to the microphone location according to the inverse square of the distance.

The comparisons show that the phased array measurements capture the spectral features well in the low and mid frequency range, but with noticeable differences for high frequencies. These trends are also representative of other operational conditions. The good agreement in the mid frequency domain is understandable from the standard beamforming method used to derive the array data; the high frequency beamforming can suffer from de-correlation effects and low frequency data usually contain significant contributions from side lobes. Since no rigorous deconvolution is applied to the beamforming results, the integrated spectra from the phased array data are not exactly the true far field noise levels. Thus, the good agreements between the phased array measurements and the free field microphone data should only be considered as an added confidence for using the results in the mid frequency domain for relative comparisons and parametric studies. 


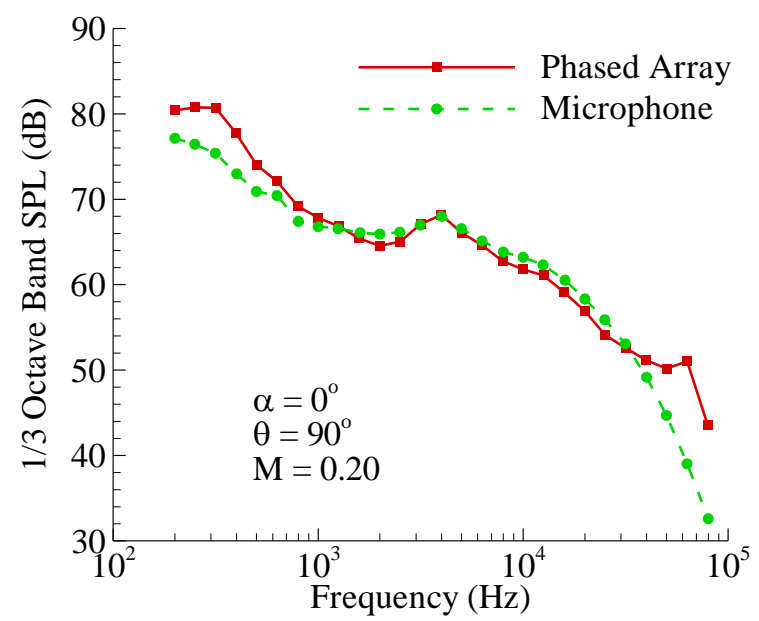

Figure 9 Comparison between phased array measurements and free field microphone data at zero degree of angle of attack

Thus, the focus of the data analysis in the rest of the paper will be in the frequency domain between about 1000 $\mathrm{Hz}$ to about $30000 \mathrm{~Hz}$, model scale as measured. For a HWB model of 3\% scale, the frequency range at full scale would then be between about $30 \mathrm{~Hz}$ to about $900 \mathrm{~Hz}$. Obviously, this is on the low side of the frequency domain for aircraft noise certification, but is the only frequency domain in which consistent parametric trends can be derived from the database, as will be seen in the following sections. Furthermore, the full scale frequency range between 30 to $900 \mathrm{~Hz}$ is relevant because slat noise is known to peak around $200 \mathrm{~Hz}$ for aircraft sizes scaled up by the factor of 3 percent. The scale factor can of course be eliminated in the analysis by the use of Strouhal number, based on the slat chord length and the mean flow velocity. In this case, the frequency range of $1000 \mathrm{~Hz}$ to $30000 \mathrm{~Hz}$ for model scale and $30 \mathrm{~Hz}$ to $900 \mathrm{~Hz}$ for full scale aircraft corresponds to a range in Strouhal number between 0.2 and 10. This clearly covers the peak Strouhal number between 1 and 2 for slat noise (e.g. Ref 7-10).

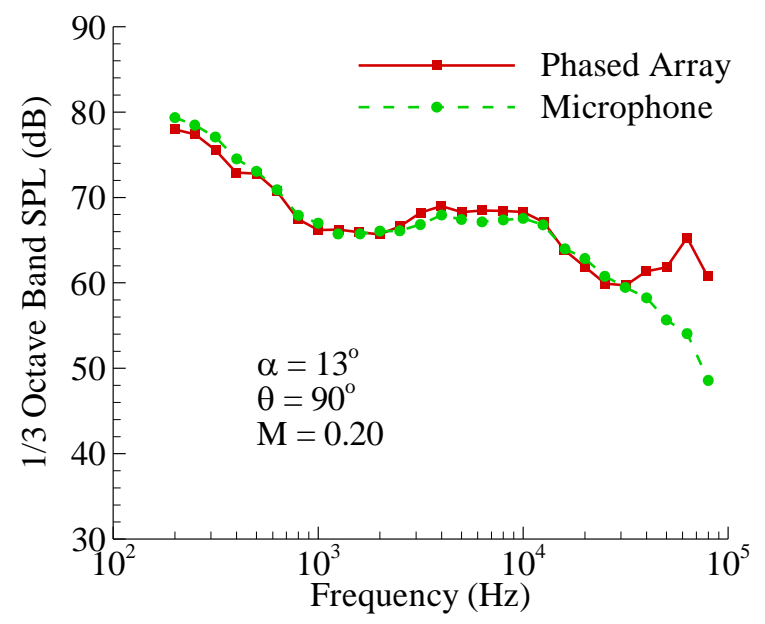

Figure 10 Comparison between phased array measurements and free field microphone data at 13 degree of angle of attack

\section{Effects of Angle of Attack on Slat Noise}

Slat noise has a complicated dependency on the aircraft angle of attack. This has been observed for conventional aircraft and has been attributed to the degree of flow separation behind the slat that is influenced jointly by the aircraft angle of attack and the slat deployment angle. With the slats deployed at a fixed angle, the case of zero angle of attack usually causes large scale flow separation, because the slat chord line is at an angle to the inflow that is approximately equal to the slat angle. Thus, the flow in this case sees the slat as a bluff body with non-streamlined shapes, causing large scale separation behind it. This is usually not a configuration used in aircraft operations, but 
serves as a good reference configuration for discussion. From this reference configuration, an increase in the aircraft angle of attack effectively reduces the angle between the slat chord line and the inflow direction, and thus, aligns the slat better with the flow. As the angle of attack increases, the flow around the slat transits from bluff body separations to flow patterns that are usually designed for high lift slats, namely, a vortical flow in the slat cove region, a high speed jet-like flow in the gap between the slat trailing edge and the main wing, and localized flow separation at the slat cusp. Due to the differences in the flow features of these two types of flow, the noise generation mechanisms can also be expected to differ in the two cases, which is why complex dependencies of slat noise on aircraft angle of attack are usually observed in airframe noise studies for conventional aircraft.

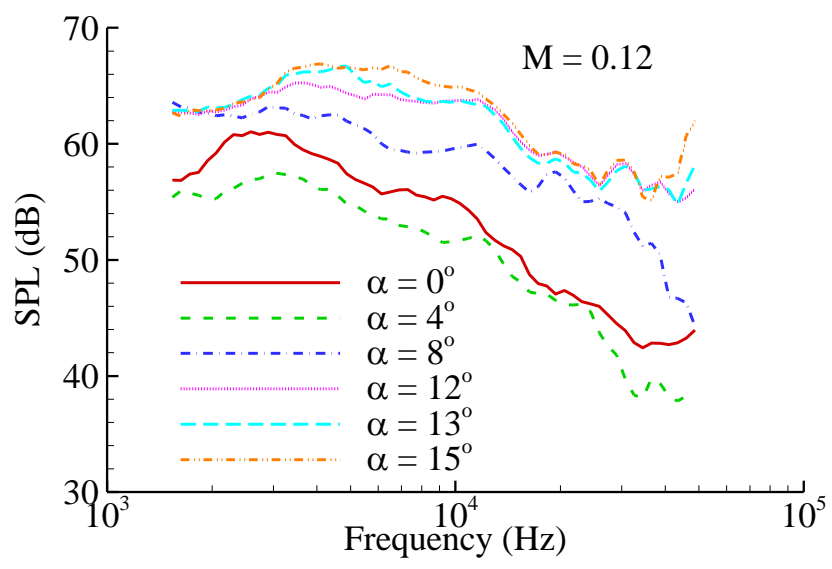

Figure 11 Dependence of HWB slat noise on aircraft angle of attack for $M=0.12$

This complex dependence similarly manifests itself for HWB aircraft, as illustrated in Figure 11 and Figure 12 which plots the HWB slat noise levels for respectively for a Mach number of 0.12 and 0.2 , each at various values of angle of attack, all measured at the overhead location of 90 degrees of emission angle with the slats deployed at 30 degrees and the elevon at 2 degrees, which is the normal approach configuration for this aircraft design. Clearly, the variations of the noise levels with increasing angle of attack are not monotonic and the variations are not uniform in frequency either, due to the source mechanism changes discussed in the previous paragraph. For both cases shown in these two figures, the lowest noise levels are for the case of 4 degrees of angle of attack. This trend is representative of other cases with different Mach numbers, different elevon settings and other measurement angles, as will be shown in subsequent discussions in the paper. Because the increment in the angle of attack is not small, the minimum noise configuration may not be at precisely 4 degrees; it is probably in the range of 3 to 5 degrees.

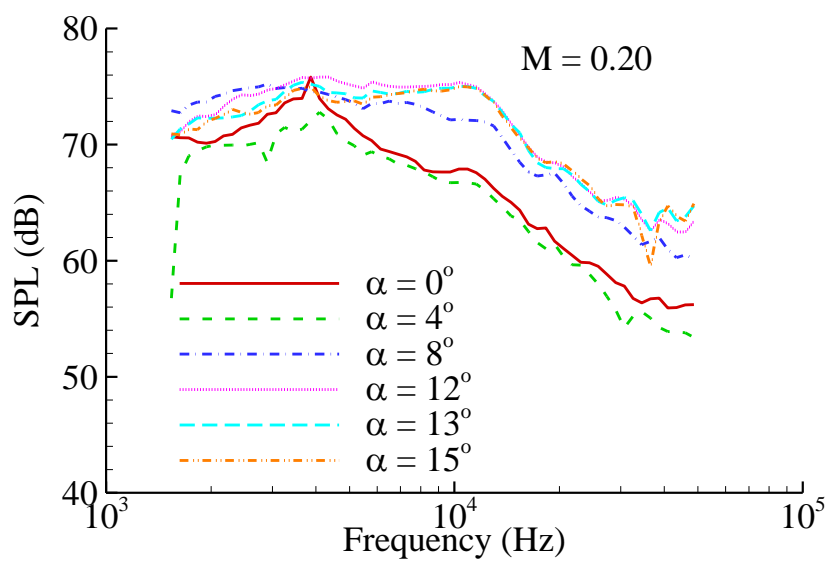

Figure 12 Dependence of $\mathrm{HWB}$ slat noise on aircraft angle of attack for $M=0.2$

It can also be seen from the figures that the spectral shapes at different angles of attack differ from each other, with those at small angles of attack dropping more rapidly above the spectral peak than those at large angles of attack. This seems to indicate noise source mechanisms that are narrow banded in frequency for the small angles of 
attack, consistent with the analysis of bluff body flow separation that is dominated by vortex shedding, and mechanisms at large angles of attack which are more broadband. It can also be clearly seen from the two figures that the spectral peak increases with the angle of attack. For the datasets in each figure, the flow Mach number and slat chord length is fixed. Thus, the Strouhal number scaling based on these two parameters would predict a fixed peak frequency for each figure. This is clearly not the case and the discrepancy results from the use of the length scale in the Strouhal number scaling. For flow generated noise, the Strouhal number scaling should be based on a length scale that characterizes the unsteady flows, their coherence length, for example (Ref 11, 12). For slat noise, the unsteady flows in the cove region and the slat-wing gap, and hence, the characteristic length of the flows, are strongly affected by the angle of attack, which brings in the dependence of the peak frequency on the angle of attack, as shown by the data. The Strouhal number scaling based on the slat chord length has been used for conventional aircraft with reasonable results because the variations of the angle of attack for conventional aircraft are not large, mostly confined between 4 to 7 degrees, leading to small variations in the peak frequency. For a much larger range of the angle of attack, as is the case considered here from zero to 15 degrees, the variations in the peak frequency also become larger. Evidently, the peak frequency is not invariant even for fixed flow Mach number and fixed slat chord length.

The increase of the peak frequency with the angle of attack, shown in Figure 11 and Figure 12, can be explained by the changes that the flows in the slat region experience as the angle of attack changes. The flow separation and its coherence length scale depend on how the incoming flow is disturbed and blocked. With the slat deployed at 30 degrees, the flow experience significant blockage at zero degree of angle of attack because the relative angle between the flow and the slat is 30 degrees. As the angle of attack increases, the relative angle between the flow and the slat decreases, until the angle of attack reaches the slat deployment angle when the flow is aligned with the slat chord and only sees the thickness of the slat. This indicates that the characteristic length of the unsteady flow is reduced as the angle of attack increases, corresponding to an increase in the characteristic frequency.

\section{Dependence on Flow Mach Number}

The dependence of slat noise spectra on the mean flow Mach number is known to follow complex patterns; instead of collapsing on a single integer power law, the spectral shapes as well as the amplitudes vary with the Mach number, as documented and discussed in previous studies for conventional aircraft slat designs (e.g. Ref 8 , 9). This is found also to be the case for the HWB slat noise and is illustrated in Figure 13 and Figure 14, respectively for zero and 12 degrees of angle of attack. The data are for the normal approach configuration with the slats deployed at 30 degrees and the elevons at 2 degrees. The data are from the array located at the polar angle of 90 degrees. In these two figures, the slat noise levels at four Mach numbers are normalized by the fifth power law and are plotted as a function of the Strouhal number based on the flow velocity and the slat chord length. The slat chord length is used for the Strouhal number scaling here because for each of the figures, the angle of attack is fixed; a different length would only shift the location of the peak Strouhal number without any changes to the relative, namely, the collapse, of the peak frequencies. This is sufficient for the discussions in this section only, which is to normalize both the frequency parameter and the amplitude by the flow velocity to discuss the dependence on the flow Mach number, and a variable length scale should be considered in general.

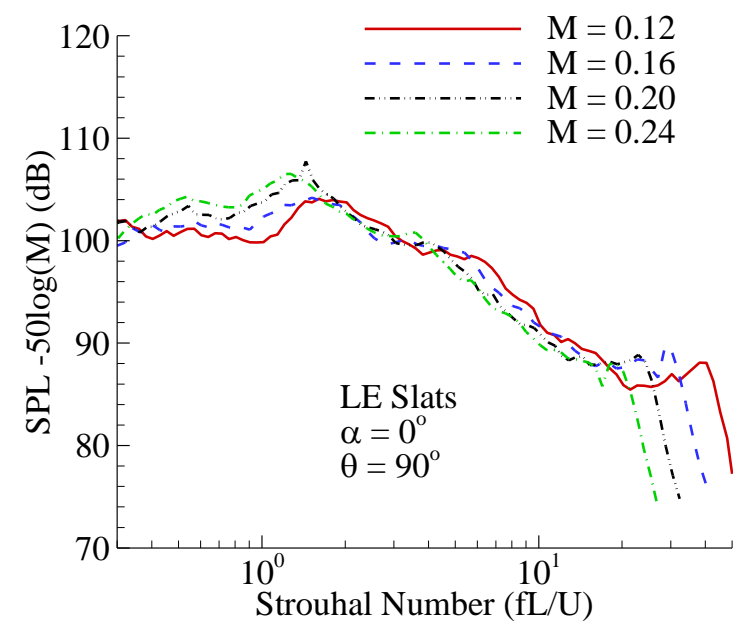

Figure 13 Dependence of HWB slat noise on mean flow Mach number at zero angle of attack 
It is clear that the fifth power law of flow Mach number does not collapse the spectral data uniformly for all the frequencies and this non-uniformity varies with the angle of attack. At small angles of attack, zero degree, for example, the collapse seems to be satisfactory for Strouhal number between about 2 to about 10, but the results show significant scatter below the Strouhal number of two, as shown in Figure 13. At large values of angle of attack, 12 degrees, for example, as shown in Figure 14, the trend seems to be the opposite; the data collapse well in the low frequency region around unity Strouhal number, but show noticeable scatter in the high frequency region, above the Strouhal number of about 3.

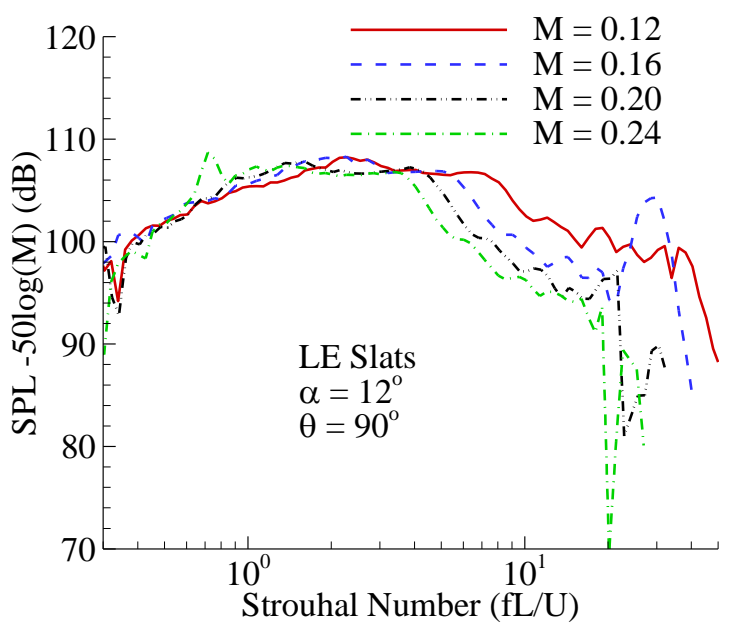

Figure 14 Dependence of HWB slat noise on mean flow Mach number at 12 degrees of angle of attack

The deviation of the noise levels from the simple fifth power law of the mean flow Mach number has been discussed in detail in Ref 8 . The main reason for this is the dependence of the spectral shape, in addition to the spectral amplitude, on the flow Mach number. The well-known fifth power law is derived for the overall sound level, which would also be applicable to the spectral levels only if the spectral shape is invariant with the flow Mach number. This is not the case for slat noise, as shown by various test data for conventional aircraft and discussed in detail in Ref 8. The data in Figure 13 and Figure 14 show that this is also the case for slat noise for HWB aircraft, and the trends in these figures are consistent with those observed in conventional aircraft. For instance, Figure 13 and Figure 14 show that the deviation of the spectral levels from the fifth power law is mainly in the high frequency domain, and the normalized datasets show higher levels for smaller Mach numbers. This means that the high frequency noise should be scaled on a power law less than the fifth, again, consistent with data from conventional aircraft slat.

\section{HWB Slat Noise Modeling and Prediction}

Slat noise modeling and prediction has been an active research topic in aeroacoustics because slats are a prominent feature in conventional aircraft design and are known to be one of the major airframe noise components (e.g. Ref 7-11). The efforts, however, have largely been focused on conventional slat designs and operating conditions, characterized by smaller sweep angles, smaller chord lengths and smaller angles of attack, in comparison with HWB designs. In principle, the prediction methodology developed in Ref 8 should be applicable to slat noise of HWB designs because the prediction model is based on the component noise source mechanisms independent of the aircraft type. To demonstrate this, predictions will be made in this section for the HWB configuration and the results will be compared with the experimental data.

Figure 16 and Figure 18 show the Sound Pressure Level (SPL) comparison respectively for the flow Mach number of 0.2 and 0.24 , at various angles of attack for the normal approach configuration with the slats deployed at 30 degrees and the elevons at 2 degrees. The data are from the array located at the polar angle of 90 degrees and the predictions are for the noise at the emission angle of 90 degrees. The levels are plotted as a function of the measured small scale frequency, but the amplitudes are shifted, by the same amount for both the prediction and the data for a fixed angle of attack, so that the curves are clearly separated from each other for easy visualization. The amount of shifting for each angle of attack is indicated in the plots. The predictions are plotted by the solid curves and the data 
by the dashed curves. It is clear that the predictions capture the overall spectral trends very well; both the spectral peaks and overall shapes are well predicted and the absolute levels are within a few $\mathrm{dB}$ between prediction and data.

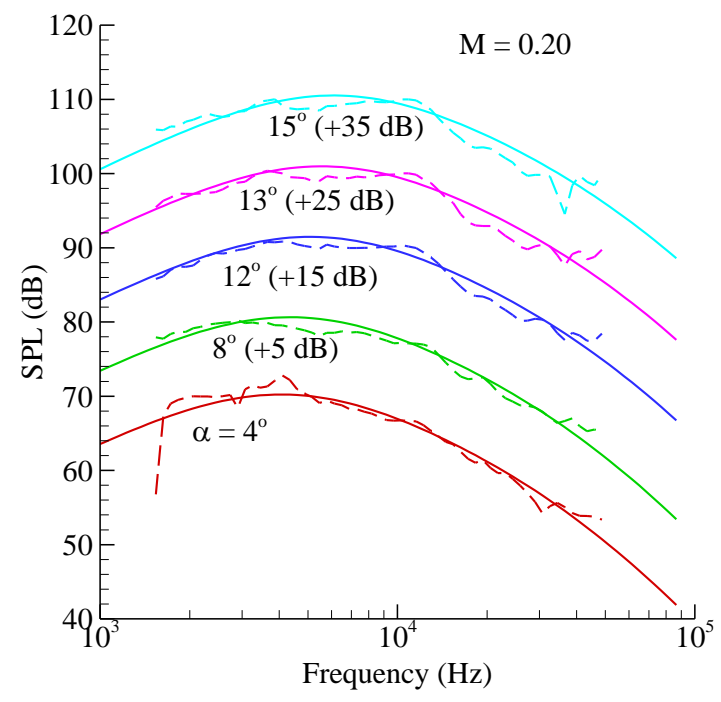

Figure 15 Comparison of SPL between prediction (solid curves) and data (dashed curves) for $M=0.2$

Both the data and the predictions in these two figures show that the spectral peaks occur at about 3000 to 4000 $\mathrm{Hz}$. If this is scaled to a full scale aircraft of the size of the Boeing 777, the scaling factor would be 3 percent, which gives the peak frequency at about $100 \mathrm{~Hz}$ for the full scale aircraft. This is lower than the peak slat noise frequency of about 200 to $300 \mathrm{~Hz}$ for the Boeing 777 aircraft, an expected outcome because of the larger slat chord length for the HWB aircraft. More detailed comparisons between the two will be given in the next section. For Strouhal number scaling based on the slat chord length and the mean flow velocity, the spectral peaks occur at about the Strouhal number of two, which is known from previously published data and clearly seen in Figure 14.

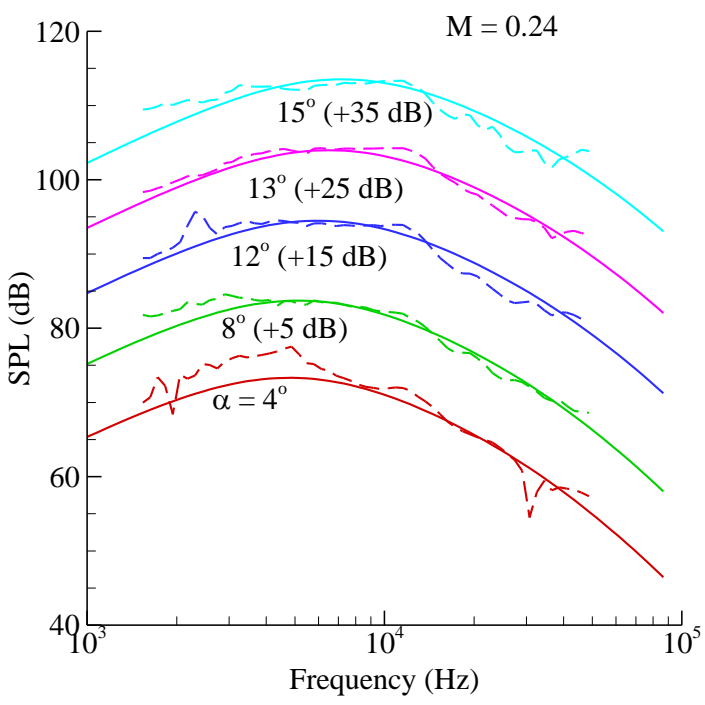

Figure 16 Comparison of SPL between prediction (solid curves) and data (dashed curves) for $M=0.24$

As discussed in the previous section and more clearly shown in Figure 16 and Figure 18, the peak frequencies of the spectra vary with the angles of attack, clearly shown by the data and correctly modeled in the predictions. It can be seen that the peak frequency shifts upwards as the angle of attack increases. At first glance, this may seem to be a surprise, because the peak frequencies are usually considered scalable by the Strouhal number based on the slat chord and the flow velocity, and thus, only depend on these two parameters. While this can be a first order estimate 
for the peak frequencies, it actually misses an important feature of the flow physics, namely, the characteristic length scale of the flow fluctuations. This length scale defines the coherence length of the unsteady flows that furnish the noise sources. The slat chord length is probably of the same order as the coherence length, but the two can be easily seen to be not equal. Thus, to accurately model and scale the peak frequencies by the Strouhal number scaling, the length scale should be the flow characteristic length, instead of simply the chord length.

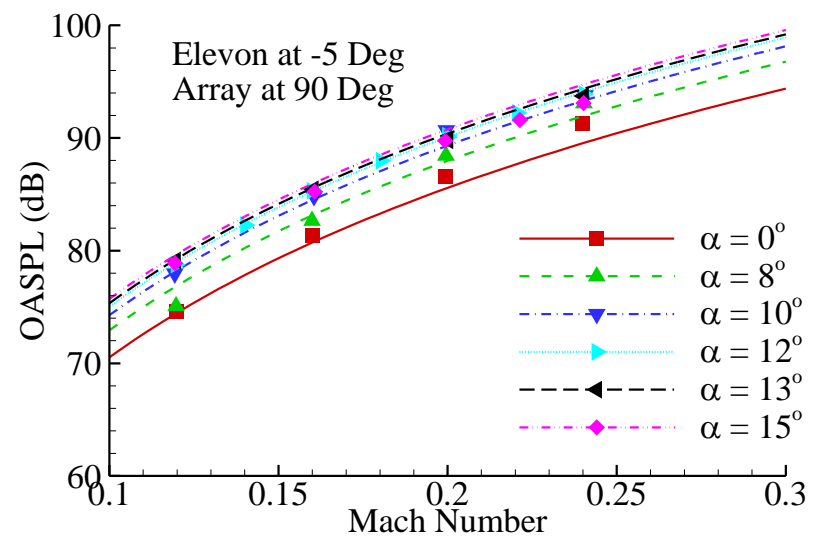

Figure 17 Comparison of Mach number dependence between prediction (curves) and data (symbols) with elevons deployed at -5 degrees

Since the characteristic length scale of the unsteady flows in the slat region is likely a function of other flow and operating parameters, the angle of attack being one, it is then not a surprise that the peak frequencies of the slat noise spectra also vary with other parameters. The effects of the angle of attack on the peak frequency shift can be understood from the flow separation in the slat cove region, which determines the coherence length scale. The intensity of the separation and its coherence length are affected by how the slats are aligned with the incoming mean flow. With the slats fixed at 30 degrees, the mean flow at zero degree of angle attack sees the most blockages, and hence, the flow separation in this case has the largest length. As the angle of attack increases towards the slat deployment angle, the flow becomes more aligned with the slat chord line, and the dimension that blocks the flow decreases until that dimension becomes the slat thickness when the angle of attack is about the same as the slat deployment angle. The decrease in the length scale, as the angle of attack increases from zero, corresponds to an increase in the peak frequency, as shown in Figure 16 and Figure 18. This feature is clearly seen in the data and is also correctly modeled in the prediction, leading to the agreement in the comparison.

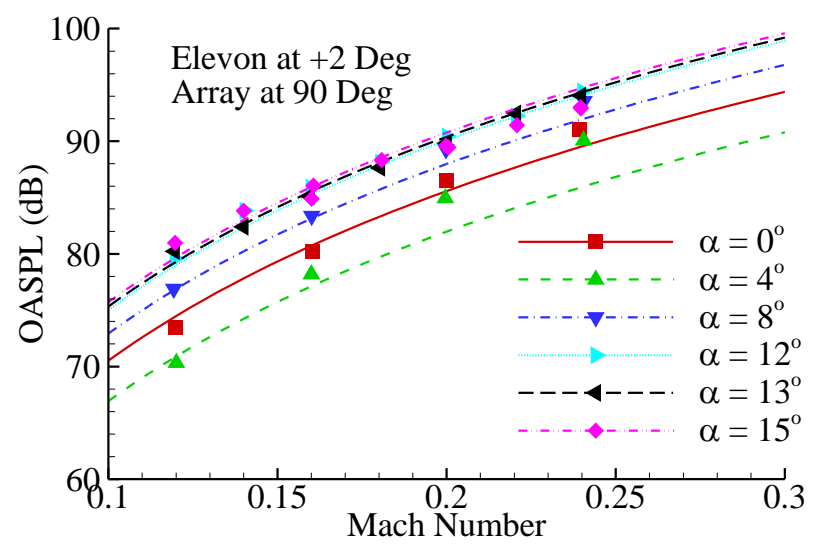

Figure 18 Comparison of Mach number dependence between prediction (curves) and data (symbols) with elevons deployed at 2 degrees

The dependence of the slat noise on the flow Mach number is shown in Figure 17 and Figure 18, with the Overall Sound Pressure Level (OASPL) plotted as a function of the flow Mach number, with various angles of attack for each diagram in the figure. Both figures are for the array location at 90 degrees and slats deployed at 30 
degrees, with Figure 17 for the elevon setting of 2 degrees and Figure 18 for -5 degrees, as indicated in each diagram. The case of negative elevon angle means that the elevons are deployed upward. The predictions are plotted as curves and the data are shown by the symbols. For all cases, good agreement between prediction and data can be seen from the figure, in both the trends in Mach number and the absolute levels of the OASPL.

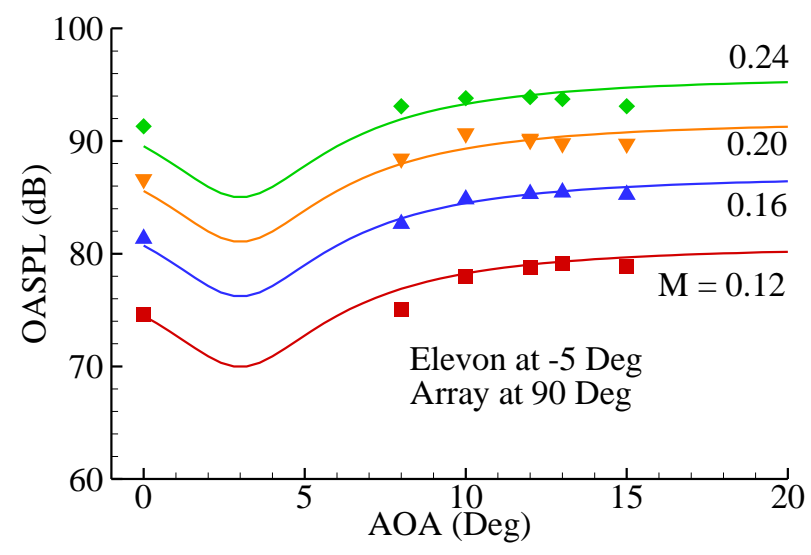

Figure 19 Comparison of the dependence on the angle of attack between prediction (curves) and data (symbols) for slats at 30 degrees with elevons deployed at -5 degrees

From the data discussed in previous sections, especially in Figure 11 and Figure 12, it is clear that the slat noise levels are a function of the angle of attack, and the effects of the angles of attack on the noise levels vary with flow Mach number. The data consistently show that the lowest slat noise comes from the case of 4 degrees of angle of attack, for various flow Mach numbers, different elevon deployment settings, and various measurement locations. Thus, even though the sparse parametric variations in the angle of attack from the test data prevents the minimum noise angle of attack from being definitely identified, it is certain that there is a minimum slat noise range for the angle of attack, in the range between about 3 to 5 degrees.

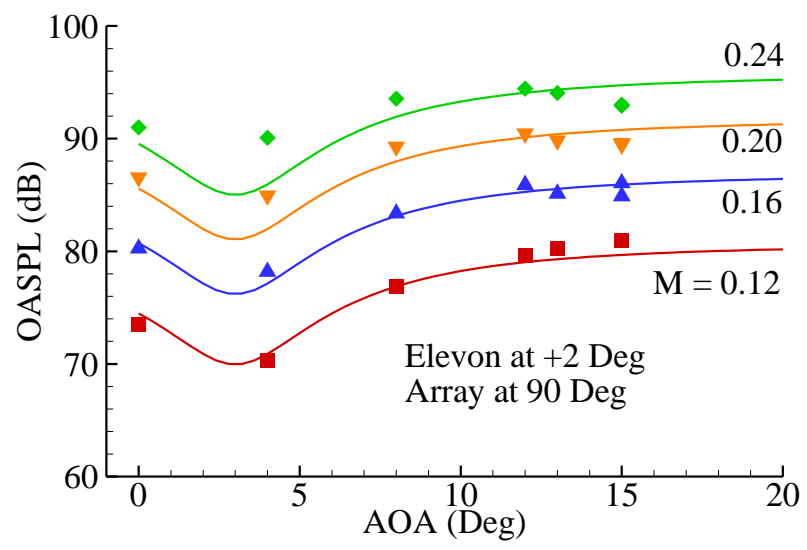

Figure 20 Comparison of the dependence on the angle of attack between prediction (curves) and data (symbols) for slats at 30 degrees with elevons deployed at 2 degrees

This feature is modeled in the prediction methodology with some results shown in Figure 19 and Figure 20, where the OASPL is plotted as a function of the angle of attack, for four flow Mach numbers in each of the plots. The results are for the measurement location of 90 degrees with the two figures respectively for two elevon settings, -5 and +2 degrees, as indicated in each diagram. The predictions are plotted by the curves and the data are shown by the symbols. Clearly, the predictions capture the effects of the angle of attack very well, for both the parametric trends and the absolute amplitudes. 


\section{Comparison with Conventional Aircraft}

The HWB slat noise may not only dominate over other components, except perhaps for the landing gear noise, but also may have levels comparable to or even higher than the slat noise of conventional aircraft. To quantify this, the data from the small scale model test are extrapolated to full scale, to an aircraft comparable to the Boeing 777 aircraft in size and functionality, and compared to the slat noise levels of the 777 aircraft. The results are given in Figure 21, with the squares for the HWB aircraft, extrapolated from small to full scale, and the diamonds for the 777 slat noise, derived from a flight test (Ref 19). The extrapolation uses a dimension scaling factor of three percent, applied to the HWB aircraft, which scales up the noise amplitude and scales down the frequencies according to standard procedures. The geometry and operational parameters of the two aircrafts are listed in Table 2. The dimensions of the slats for the HWB aircraft are scaled up by dividing the small scale dimensions by 0.03 . In addition, the frequencies of the small scale test data are scaled down by the multiplying factor 0.03 . The amplitudes of the noise are also scaled up by the square of the scaling factor. All the data are extrapolated to the distance of 394 feet, which is the altitude for aircraft noise certification at approach conditions, at the observation angle of 90 degrees, namely, the overhead location.

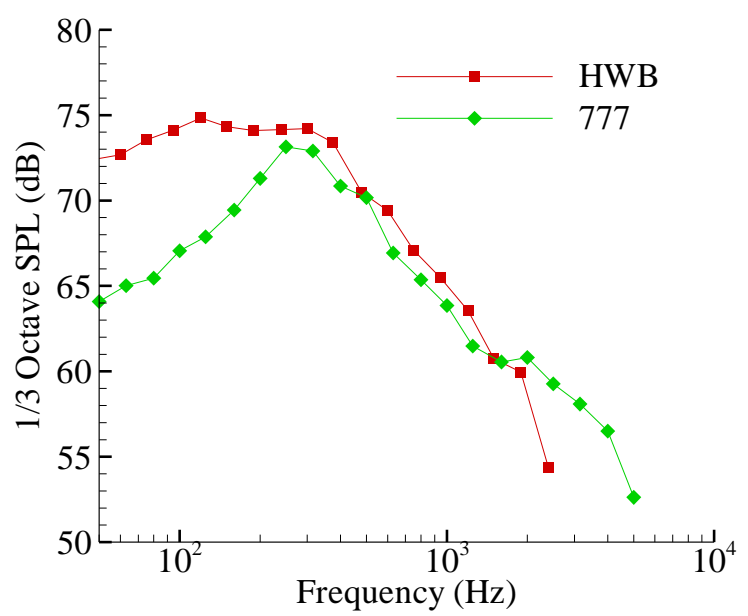

Figure 21 Comparison of slat noise levels between HWB and 777 aircraft

A striking conclusion from the data shown in Figure 21 is that the HWB aircraft generates more slat noise than the Boeing 777 aircraft, even though the former flies at a lower Mach number than the latter, 0.2 for the HWB and 0.25 for the Boeing 777. It is known that the peak spectral levels of slat noise scale on the fifth power of Mach number. According to this, the HWB slats would have lower noise levels, by about $4.8 \mathrm{~dB}$, in comparison with the levels for the Boeing 777 aircraft, due to the lower flight Mach number. This is obviously not the case shown by the data which include other effects, as well as the effects of Mach number. Instead, the HWB aircraft generates substantially more noise in the low frequency region around about $100 \mathrm{~Hz}$ than the Boeing 777 does, by as much as $10 \mathrm{~dB}$, and has levels about $2 \mathrm{~dB}$ higher than the Boeing 777 for frequencies from about 100 to $1000 \mathrm{~Hz}$. The higher noise levels at low frequencies from the HWB aircraft is partially due to the larger slat chord length, which leads to lower peak frequency, and partially due to the increase of noise amplitude that is proportional to the slat chord length. The overall higher slat noise levels of the HWB aircraft are, however, largely due to the different slat operating conditions. From Table 2, it is clear that the source area, approximately the product of the slat chord and span length, is comparable between the two cases, respectively 38515.6 square inches for the HWB and 31899.3 square inches for the 777, corresponding to a difference of about $0.8 \mathrm{~dB}$ in noise levels. Thus, the noise advantage of the HWB, of about $4.8 \mathrm{~dB}$, from the Mach number difference, must have been offset by an increase in the source density or source strength. This source increase comes from the slat sweep angle and the aircraft angle of attack, for both of which the HWB aircraft has higher values. The data and prediction given in previous sections confirm this; for example, the difference in the angle of attack can lead to a noise increase for the HWB aircraft of about $8 \mathrm{~dB}$ in a broad frequency range. This $8 \mathrm{~dB}$ noise increase will of course be partially offset by the $4.8 \mathrm{~dB}$ noise benefit due to the lower Mach number, which is probably why the HWB slat noise in Figure 21 is seen about 2 to 3 dB higher than the slat noise of the Boeing 777 aircraft for the high frequency range.

The result shown in Figure 21 is a valuable conclusion on HWB slat noise. It not only quantifies the noise levels, but also illustrates the shortfall of simply using the Mach number scaling to infer a lower noise level for the HWB aircraft. It should be recognized that the Mach number scaling law, being approximately the fifth power for slat 
noise, is applicable only if all other conditions, including both design parameters and operating conditions, are the same, which is clearly not the case when comparing the HWB aircraft with conventional aircraft. In this case, changes in other conditions may alter the source characteristics, causing noise changes that are not governed by the Mach number scaling law. In the case of HWB slat noise, the data show that the acoustic benefit of lower Mach number for the HWB aircraft is completely offset and taken over by the penalty due to the increase in noise source strength, mostly due to the larger angle of attack.

Table 2 Geometry and operation parameters of HWB and 777 aircraft

\begin{tabular}{lcc}
\hline & $H W B$ & 777 \\
\hline Chord Length (inch) & 36.3 & 27.1 \\
Span Length (inch) & 1062.5 & 1178.4 \\
Slat Angle (degree) & 30 & 30 \\
Sweep Angle (degree) & 37.8 & 34 \\
Angle of Attack (degree) & 12 & 6 \\
Flap Setting & - & 30 \\
Elevon Angle (degree) & 5 & - \\
Flight Mach Number & 0.2 & 0.25 \\
\hline
\end{tabular}

\section{Conclusions}

An analysis has been presented for the slat noise of the HWB aircraft design, revealing various functional trends of the noise levels for parameters such as the flow Mach number and the aircraft angle of attack. It has been shown that the overall slat noise levels approximately follow the fifth power law in flow Mach number, but the dependence of the noise spectra on the Mach number is much more complicated, with effects manifesting themselves not only in the amplitudes, but also in the spectral shapes, confirming features previously discussed for slat noise of conventional aircraft. The effects of the aircraft angle of attack on the slat noise have been shown to be both in the noise levels and in the peak frequencies. For the amplitudes, the slat noise seems to assume a minimum in the range of about 3 to 5 degrees of angle of attack, and increases in level as the angle of attack moves away from this minimum noise range. For the peak frequencies, it has been shown that an increase in the angle of attack, from zero to the slat deployment angle, causes an upwards shift in the peak frequencies, a feature that can be explained by the decrease of the characteristic length scale of the flow separation in the slat flow region as the angle of attack increases. All these features have been modeled in slat noise prediction methodologies, which have been shown to agree well with the experimental data, not only capturing the correct parametric trends but also accurately predicting the absolute amplitudes, especially for the cases of large angles of attack for which test data were not previously available

One of the main conclusions has been that the HWB slat noise may have levels comparable to or even higher than those of conventional aircraft, even though the HWB aircraft usually has a lower flight Mach number. This may seem to be a surprise since airframe noise is usually scaled on either the fifth or the sixth power law on Mach number; a difference between 0.2 for HWB aircraft and 0.25 for conventional aircraft would correspond to a noise reduction of about $5 \mathrm{~dB}$. However, this assumes that all the other conditions are the same between the two aircrafts being compared, including operating conditions and aircraft designs, which is obviously not the case. The two aircraft have drastically different designs and operate at different conditions. Thus, the Mach number scaling laws should not be blindly applied. Instead, the individual noise components should be examined to account for the unique features of each design detail that may impact the noise source mechanisms. In comparison with conventional aircraft designs, the slats of the HWB aircraft have larger dimensions and larger sweep angles. Furthermore, the HWB aircraft is designed to operate at large angles of attack, usually above 10 degrees, compared with conventional aircraft that operate in the range of 4 to 7 degrees. All of these increase levels of the slat noise of the HWB aircraft, which more than offsets the benefit of its lower flight Mach number. It has been shown by the test data that the large angles of attack alone can increase the slat noise by as much as $8 \mathrm{~dB}$ from the levels of conventional aircraft slat noise. By scaling the model test data to a full scale configuration that is comparable to the Boeing 777 aircraft in dimensions and functionalities, it has been shown that the HWB has more slat noise than the Boeing 777 aircraft. 
From the data and analysis for the slat noise component, a very low fidelity estimate can be offered for the relative levels of the total airframe noise between the HWB design and the conventional aircraft. It can be approximately assumed that the slats, the flap side edges and the landing gears equally contribute to the airframe noise of conventional aircraft, while only the slats and the landing gears contribute to the HWB airframe noise since its design does not use flaps. The lack of flaps in HWB design has an acoustic benefit of about $1.8 \mathrm{~dB}$ in total airframe noise. Another $1 \mathrm{~dB}$ benefit may be assumed for the landing gear noise, due to the aggregate effect of lower flight Mach number of the HWB aircraft and the location of the main landing gears. However, this resultant $2.8 \mathrm{~dB}$ noise reduction may be largely offset by the increase in HWB slat noise, ranging from $2 \mathrm{~dB}$ in the mid frequency region to up to $10 \mathrm{~dB}$ in the low frequency region. This is clearly a very rudimentary estimate, but it does illustrate that the HWB total airframe noise may not been noticeably lower, if not higher, than conventional aircraft, even though the former has a much lower flight Mach number than the latter and have no flaps.

\section{Acknowledgments}

The work reported here was sponsored by the NASA Environmentally Responsible Aviation Project under NASA SMAAATAV Contract NNL04AA11B, Task Order NNL10AA71T. Dan Vicroy, NASA Langley, is acknowledged for making available the $3 \%$ BWB model for the LSAF experiment.

\section{References}

1 Clark L. R. \& Gerhold C. H. "Inlet Noise Reduction by Shielding for the Blended Wing Body Airplane," AIAA Paper 99-1937, presented at the 5th AIAA/CEAS Aeroacoustics Conference, Seattle, WA, 1999.

2 Hill G. A., Brown S. A., Geiselhart K. A. \& Burg C. M. "Integration of Propulsion Airframe Aeroacoustic Technologies and Design Concepts for a Quiet Blended Wing Body Transport," AIAA Paper 2004-6306, 2004.

3 Thomas R. H., Burley C. L. \& Olson E. D. "Hybrid Wing Body Aircraft System Noise Assessment with Propulsion Airframe Aeroacoustic Experiments," International Journal of Aeroacoustics, 11 (3+4), 369-410, 2012.

4 Czech M. J., Thomas R. H. \& Elkoby R. "Propulsion Airframe Aeroacoustic Integration Effects of a Hybrid Wing Body Aircraft Configuration," International Journal of Aeroacoustics, 11 (3+4), 335-368, 2012.

5 Bonet J. T., Schellenger H. G., Rawdon B. K., Elmer K. R., Wakayama S. R., Brown D. \& Guo Y. P. "Environmentally Responsible Aviation (ERA) Project - N+2 Advanced Vehicle Concepts Study and Conceptual Design of Subscale Test Vehicle (STV),” NASA Contract Report, December 2011.

6 Guo Y. P. \& Thomas R. H. "On System Noise Assessment for Hybrid Wing Body (HWB) Aircraft" AIAA 2013-

7 Guo Y. P. “A Discrete Vortex Model for Slat Noise Prediction” AIAA Paper 2001-2157, 2001.

8 Guo Y. P. "Slat Noise Modeling and Prediction" Journal of Sound Vibration. 331, 3567-3586, 2012.

9 Dobrzynski W. \& Pott-Pollenske M. "Slat Noise Source Studies for Farfield Noise Prediction" AIAA 20012158, 2001.

10 Mendoza J. M., Brooks T. F. \& Humphery W. M. "Aeroacoustic Measurements of a Wing/Slat Model” AIAA Paper 2002-2604, 2002.

11 Guo Y. P., Joshi M. C., Bent P. H. \& Yamamoto K. J. 2000 Surface pressure fluctuations on aircraft flaps and their correlation with far field noise. Journal of Fluid Mechanics 415 pp 175-202.

12 Guo Y. \& Joshi M. "Noise Characteristics of Aircraft High Lift System," AIAA Journal, 41(7), 1247-1256, 2003.

13 Dobrzynski, W., Nagakura, K. Gehlhar, B. and Buschbaum, A. "Airframe Noise Studies on Wings with Deployed High-Lift System” AIAA Paper 1998-2337, June 1998

14 Brooks T. F. \& Humphreys W. M. Jr. "Flap Edge Aeroacoustic Measurements and Predictions," Journal of Sound and Vibration. 261, 31-74, 2003.

15 Liebeck, R.H., "Design of the Blended-Wing-Body Subsonic Transport," AIAA Paper No. 2002-0002.

16 Owens, D.B., Brandon, J.M., Croom, M.A., Fremaux, C.M., Heim, E.H., and Vicroy, D.D., "Overview of Dynamic Test Techniques for Flight Dynamics Research at NASA LaRC," AIAA Paper No. 2006-3146.

17 Shields, F.D., and Bass, H.E., "A Study of Atmospheric Absorption of High Frequency and Application to Fractional Octave Bands of Noise," NASA Contractor Report 2760, 1976.

18 Dougherty, R. P., "Beamforming in Acoustic Testing," Aeroacoustic Measurements, edited by T. S. Mueller, Springer-Verlag, New York, 2002. 
19 Herkes, W.H., Olsen, R.F., and Uellenberg, S., “The Quiet Technology Demonstrator Program: Flight Validation of Airplane Noise-Reduction Concepts," AIAA Paper No. 2006-2720, presented at the 12th AIAA/CEAS Aeroacoustics Conference, Cambridge, Massachusetts, May 8-10, 2006. 